\title{
Discretionary medical reporting of potentially unfit drivers: a questionnaire-based survey in Southeast Switzerland
}

\author{
Sebastian Eggert • Michael J. Thali • Matthias Pfäffli
}

Received: 20 October 2010 /Accepted: 11 April 2011 /Published online: 2 May 2011

(C) Springer-Verlag 2011

\begin{abstract}
In Switzerland, every physician has the right to report a patient that is potentially unfit to drive to the licensing authority without violating medical confidentiality. Verified information regarding physicians' attitudes concerning this discretionary reporting and the frequency of such reports are not available. In order to answer these questions, 635 resident physicians were sent a questionnaire. The response rate was $52 \%$. On average, the responding physicians-for all specialties-reported 0.31 patients (SD $0.64,95 \%$ CI $0.24-0.38$ ) in the year before the survey and 1.00 patient (SD 1.74, 95\% CI $0.81-1.20)$ in the past 5 years. Seventy-nine percent of the responding physicians indicated knowing the current legal requirements for driving in Switzerland. In applied logistic regression analysis, only two factors correlate significantly with reporting: male sex (odds ratio 5.4) and the specialty "general medicine" (odds ratio 3.4).
\end{abstract}

\section{S. Eggert}

Institute of Pathology and Forensic Medicine,

Cantonal Hospital of Grisons,

Loestrasse 170,

7000 Chur, Switzerland

\section{J. Thali}

Institute of Forensic Medicine, University of Bern,

Bühlstrasse 20,

3012 Bern, Switzerland

\section{Pfäffli ( $\bowtie)$}

Department of Traffic Sciences, Institute of Forensic Medicine,

University of Bern,

Bubenbergplatz $4 \mathrm{~b}$,

3001 Bern, Switzerland

e-mail: matthias.pfaeffli@irm.unibe.ch
Ninety-seven percent of the physicians were against abolishing medical discretionary reporting and $29 \%$ were in favor of introducing mandatory reporting. The great majority of the questioned physicians supported the discretionary reporting of drivers that are potentially unfit to drive as currently practiced in Switzerland. The importance and the necessity of a regular traffic medicine-related continuing education for medical professionals are shown by the low number of reports per physician.

Keywords Fitness to drive - Discretionary reporting · Mandatory reporting $\cdot$ Medical requirements $\cdot$ Driving . Survey

\section{Introduction}

Substance abuse and somatic diseases can have a relevant influence on fitness to drive [1-3]. In most countries, following the issuing of a driver's license to private persons, there is no periodic medical examination of driving fitness while such could be planned for professional drivers. At best, the licensing authorities can learn about existing driving-related illness via notifications from the driver himself or herself, from his or her relatives, or from the police as well as via medical reporting. In some countries, like the USA, Canada, Australia, and the UK, there exist legal regulations concerning voluntary or compulsory notification about persons who are unfit to drive by physicians to the licensing authorities. Other countries, for example, Germany, Belgium, and The Netherlands, have not regulated such reporting by law [4-7]. 
In Switzerland, since 1975, physicians have the right to report a suspicion of the missing driving fitness of a patient to the licensing authorities:

Every physician can report to the supervisory authority for doctors and to the authorities who are responsible for issuing and revoking driving licenses persons who are not able to drive a motor vehicle safely due to somatic or mental illness or infirmity or because of addiction [8].

Since, currently, no verified information is available about the attitude of physicians toward this right of reporting as well as about the frequency of the reports, the following survey was made.

\section{Materials and methods}

\section{Study design}

Using questionnaires, we carried out a postal survey that was sent out to all the physicians with their own practiceindependent of specialty - in the Swiss cantons of Glarus, Graubünden (without the Italian speaking part), Schwyz and Uri (ca. 396,000 inhabitants whereas Switzerland has ca. 7,786,000 inhabitants) $[9,10]$. The physicians were selected from an online physicians directory of the Swiss Medical Association $(n=635)$ [11]. The structure of the queried population can be seen in Table 1 .

The questionnaires were devised based on an examination of the literature and talks with physicians about the problems concerning medical reporting. A pretest with 20 physicians of various specialties was performed, the results of which were not included in the investigation results.

The questionnaire comprised 19 questions. Six of them had demographic contents (sex, age, specialist title, country

Table 1 Survey characteristics

\begin{tabular}{lll}
\hline & Respondents & Survey population \\
\hline Total $(n)$ & 328 & 635 \\
Thereof blank questionnaires & 11 & \\
Response rate (\%) & & \\
Overall & 52 & \\
Without blank questionnaires & 50 & \\
Sex (\%) & & 80 \\
Male & 84 & 20 \\
Female & 16 & \\
Specialty (\%) & & 35 \\
General Medicine & 43 & 14 \\
Internal Medicine & 15 & 8 \\
Psychiatry & 9 & 43 \\
Other & 33 & \\
\hline
\end{tabular}

that granted the specialty certification, canton where the practice is located, number of years of practice).

In 13 questions, the attitude of the medical profession towards reporting those unfit to drive were queried (have already submitted medical reports, number of reports in the past year/past 5 years, reasons for and against reporting, knowledge of medical requirements, revoking discretionary reporting, introduction of mandatory reporting, negative reactions to the reporting, introduction of a countrywide standardized report form, importance of checking examinations, source of information concerning traffic medicine, improvement of education in traffic medicine). For answering, the possibilities were "yes/ no" or "no opinion"; for questions with multiple answers, up to seven responses were possible. Age and years in the practice were asked in terms of classes. The questionnaire (in German) can be requested from the corresponding author.

In order to boost the number of returned questionnaires, a cover letter addressed personally as well as a prepaid reply envelope were included.

The survey was carried out anonymously. The reply envelopes and the questionnaire were not tagged. The reply envelopes were discarded, and the questionnaires were handed over to the data analysts.

Due to the amount of data, the results from the questions having to do with continuing education about traffic-related medicine are given within the framework of a further investigation.

Due to the investigation design and according to information provided by this organization, an approval of the responsible ethics commission (cantonal ethics commission of Bern) was not necessary.

Data analysis

The questionnaire answers were analyzed using the SPSS Statistics 17.0 program for Windows (SPSS Inc., Chicago, USA).

The results shown in Tables 1, 4, 5, and 6 were obtained by using descriptive data analysis.

The results from groups of the general practitioners, the internists, and the psychiatrists were separately evaluated while the other specialties, due to the small number, were subsumed under "other."

For physicians with multiple specialties, the group assignment took place according to the following priorities:

1. Specialty "general medicine" and further certification(s): assigned to the "general medicine" group

2. Specialty "internal medicine" and further certification(s): assigned to the "internal medicine" group

3. Multiple specialty certification(s), but without "general medicine" and "internal medicine": assigned to the "other specialty" group. 
The answers to the question about "have already submitted medical reports yes/no" and the number of the reports submitted up until now were analyzed using exploratory data analysis. Two or more than two not normal distributed independent samples with at least one interval scaled variable were compared using a Mann-Whitney $U$ test or Kruskal-Wallis $H$ test. The comparison of nominaland ordinal-scaled variables was performed using the Chisquared test. Multivariate testing of factors influencing reporting and the knowledge of minimal requirements was done by logistic regression analysis (SPSS-variable selection method "enter" was used, a variable selection in which all variables are entered in a single step).

The level for statistical significance was set to $p<0.0022$ (with Bonferroni correction for multiple comparisons, without correction $p<0.05$ ).

\section{Results}

The response rate amounted to $52 \%$ (50\% if returned nonfilled-out questionnaires are excluded). In comparison to the overall population, male physicians and general practitioners were over represented while the "other specialty" group was under represented (Table 1). From the responding physicians, no negative reactions to the survey came back.

Forty percent of all the physicians have already reported patients to the responsible division of motor vehicles. Of the male physicians, it was $46 \%$, of the females $10 \%(p<0.0001)$. On average, in the 12 months before the survey, 0.31 patients (SD $0.64,95 \%$ CI 0.24 0.38 ) were reported by the physicians; in the past 5 years, 1.00 patients (SD $1.74,95 \%$ CI $0.81-1.20$ ). Male physicians and physicians who knew the medical requirements for driving fitness as well as general practitioners reported statistically significantly more frequently. No significant differences in the reporting behavior existed among the categories of age and of years of practice activity as well as among internists and psychiatrists in comparison to the groups of the other specialties (Table 2). Seventy-nine percent of the responding physicians declared knowing the current medical requirements for driving in Switzerland.

Table 2 Proportion of physicians with/without medical reporting and number of medical reports in the last year/the last 5 years per physician

\begin{tabular}{|c|c|c|c|c|c|c|c|c|c|c|c|}
\hline & \multicolumn{3}{|l|}{ Reporting } & \multicolumn{4}{|c|}{ Reporting last year $(n=315)$} & \multicolumn{4}{|c|}{ Reporting in the past 5 years $(n=315)$} \\
\hline & Yes \% $(n)$ & No $\%(n)$ & & Mean & $\mathrm{SD}$ & $95 \% \mathrm{CI}$ & & Mean & SD & $95 \% \mathrm{CI}$ & \\
\hline Total & 40 (127) & $60(188)$ & & 0.31 & 0.64 & $0.24-0.38$ & & 1.00 & 1.74 & $0.81-1.20$ & \\
\hline \multicolumn{12}{|l|}{ Sex } \\
\hline Male & $46(121)$ & $54(143)$ & & 0.35 & 0.67 & $0.27-0.43$ & & 1.14 & 1.77 & $0.92-1.35$ & \\
\hline Female & $10(5)$ & $90(44)$ & $p<0.0001$ & 0.1 & 0.36 & $0.00-0.20$ & $p=0.0061$ & 0.32 & 1.46 & $0.00-0.74$ & $p<0.0001$ \\
\hline \multicolumn{12}{|l|}{ Age } \\
\hline$<35$ years & $0(0)$ & $100(3)$ & & 0 & 0 & 0 & & 0 & 0 & 0 & \\
\hline $36-45$ years & $34(23)$ & $66(45)$ & & 0.32 & 0.60 & $0.18-0.47$ & & 0.82 & 1.51 & $0.46-1.19$ & \\
\hline $46-55$ years & $40(47)$ & $60(71)$ & & 0.27 & 0.55 & $0.17-0.37$ & & 0.97 & 1.82 & $0.64-1.30$ & \\
\hline $56-65$ years & $45(48)$ & $55(58)$ & & 0.38 & 0.76 & $0.23-0.52$ & & 1.23 & 1.90 & $0.87-1.60$ & \\
\hline$>65$ years & $47(9)$ & $53(10)$ & $p=0.3193$ & 0.26 & 0.56 & $0.00-0.53$ & $p=0.7845$ & 0.82 & 1.10 & $0.29-1.34$ & $p=0.3401$ \\
\hline \multicolumn{12}{|l|}{ Years in practice } \\
\hline$<10$ & $33(32)$ & $67(66)$ & & 0.27 & 0.56 & $0.16-0.38$ & & 0.78 & 1.45 & $0.49-1.07$ & \\
\hline $11-20$ & $38(37)$ & $62(60)$ & & 0.28 & 0.55 & $0.17-0.39$ & & 0.93 & 1.79 & $0.57-1.29$ & \\
\hline $21-30$ & $50(48)$ & $50(49)$ & & 0.38 & 0.74 & $0.23-0.53$ & & 1.27 & 1.87 & $0.89-1.64$ & \\
\hline$>30$ & $48(10)$ & $52(11)$ & $p=0.0931$ & 0.38 & 0.86 & $0.00-0.77$ & $p=0.8753$ & 1.26 & 2.14 & $0.29-2.24$ & $p=0.1459$ \\
\hline \multicolumn{12}{|c|}{ Minimum requirements known } \\
\hline Yes & $47(115)$ & $53(132)$ & & 0.37 & 0.69 & $0.28-0.46$ & & 1.17 & 1.87 & $0.94-1.41$ & \\
\hline No & $17(11)$ & $83(54)$ & $p<0.0001$ & 0.09 & 0.34 & $0.01-0.18$ & $p=0.0009$ & 0.37 & 0.94 & $0.14-0.60$ & $p=0.0001$ \\
\hline \multicolumn{12}{|l|}{ Specialty } \\
\hline General medicine & $55(75)$ & $45(61)$ & & 0.48 & 0.78 & $0.35-0.61$ & $p<0.0001^{\mathrm{a}}$ & 1.45 & 2.00 & $1.11-1.79$ & $p<0.0001^{\mathrm{a}}$ \\
\hline Internal medicine & $46(21)$ & $54(25)$ & & 0.30 & 0.59 & $0.13-0.48$ & $p=0.0179^{\mathrm{a}}$ & 1.05 & 1.74 & $0.54-1.57$ & $p=0.0059^{\mathrm{a}}$ \\
\hline Psychiatry & $36(10)$ & $64(18)$ & & 0.29 & 0.60 & $0.05-0.52$ & $p=0.0784^{\mathrm{a}}$ & 1.29 & 2.34 & $0.38-2.19$ & $p=0.0318^{\mathrm{a}}$ \\
\hline Other & $20(21)$ & $80(84)$ & $p<0.0001$ & 0.11 & 0.35 & $0.04-0.18$ & & 0.33 & 0.72 & $0.19-0.47$ & \\
\hline
\end{tabular}

SD standard deviation; $95 \%$ CI 95\% confidence interval

${ }^{a}$ vs. others 
In order to test the influencing factors on reporting and the knowledge of minimal requirements, a logistic regression analysis was applied.

In this analysis, only two factors correlate significantly with reporting. These are male sex (odds ratio 5.4) and general medicine (odds ratio 3.4). The knowledge of minimal requirements lies just above the level of significance $(p=0.0048)$. The only significant factor with influence on the knowledge of minimal requirements is the specialty "general medicine" (odds ratio 4.6; Table 3).

Of the physicians who had already sent reports to the division of motor vehicles, the most frequent reasons they gave were the safety of all road users and the safety of their patients (98\% and 58\%, respectively, for all physicians). It is to be noted that as the reason for reporting, psychiatrists gave legal protection of physicians and noncompliance of the patients far more frequently than physicians of other specialties (each $70 \%$ against $29-43 \%$ and $24-38 \%$, respectively). Table 4 shows in detail the answers according to the reasons for reporting.

Of the physicians who had up until now not sent any reports to the department of motor vehicles, the reasons most frequently given for not reporting were: no cause to do so and missing relevance of the driving fitness problem to their specialty (63\% and $24 \%$, respectively). Special attention should be made concerning two points: $33 \%$ of the psychiatrists gave as the reason for not reporting a patient the missing relevance of driving fitness to their specialty (general practitioners and internists: $5 \%$ and $8 \%$, respectively). An above average number of general practi- tioners gave as the reason for not reporting the protection of the physician/patient relationship (23\%, compared with $8 \%$ for internists and $6 \%$ for psychiatrists). Eleven percent of all physicians gave as the reason for their not reporting up until now an ignorance of the right to report. Further results can be taken from Table 5 .

Finally, the results from the questionnaire showed that the abolition of the medical discretionary reporting would be quite clearly rejected (rejection rate in the various examined groups was between $95 \%$ and $100 \%$; see Table 6).

In the examined groups, the introduction of mandatory medical reporting when there is suspicion of missing driving fitness received agreement rates of $24-50 \%$; when calculated for all the physicians $29 \%$ (see Table 6).

\section{Discussion}

In comparison with other surveys concerning driver fitness problems, the response rate at $52 \%$ was in the average range [12-22]. To be especially noticed is the fact that practicing physicians were also approached who, in their specialty, have little or no relation to driving fitness problems (e.g., pediatricians, gynecologists).

The present investigation does not claim to be representative for all of Switzerland. Nevertheless, due to the rate of return that was achieved, the survey can be considered to be representative for the investigated, somewhat rural and small town areas. In terms of Switzerland, a tendency
Table 3 Logistic regression: factors influencing reporting and knowledge of minimal requirements

OR odds ratio; $95 \%$ CI $95 \%$ confidence interval

\begin{tabular}{|c|c|c|c|c|c|c|}
\hline & \multicolumn{3}{|c|}{ Reporting } & \multicolumn{3}{|c|}{ Minimal requirements } \\
\hline & OR & $95 \% \mathrm{CI}$ & & OR & $95 \% \mathrm{CI}$ & \\
\hline \multicolumn{7}{|l|}{ Sex $($ base $=$ female $)$} \\
\hline male & 5.417 & $1.966-14.925$ & $p=0.0011$ & 1.545 & $0.712-3.350$ & $p=0.2710$ \\
\hline \multicolumn{7}{|l|}{ Age $($ base $=>65$ ) } \\
\hline$<35$ years & 0 & 0 & $p=0.9992$ & 1.448 & $0.064-32.620$ & $p=0.8157$ \\
\hline $36-45$ years & 1.147 & $0.193-6.812$ & $p=0.8800$ & 1.102 & $0.182-6.689$ & $p=0.9160$ \\
\hline $46-55$ years & 1.164 & $0.249-5.446$ & $p=0.8468$ & 2.380 & $0.504-11.241$ & $p=0.2737$ \\
\hline $56-65$ years & 0.813 & $0.204-3.243$ & $p=0.7692$ & 2.167 & $0.536-8.759$ & $p=0.2777$ \\
\hline \multicolumn{7}{|c|}{ Years in practice (base $=>30$ ) } \\
\hline$<10$ & 0.513 & $0.095-2.777$ & $p=0.4389$ & 1.238 & $0.202-7.603$ & $p=0.8176$ \\
\hline $11-20$ & 0.552 & $0.124-2.449$ & $p=0.4343$ & 0.698 & $0.143-3.405$ & $p=0.6567$ \\
\hline $21-30$ & 0.818 & $0.216-3.094$ & $p=0.7664$ & 0.963 & $0.227-4.092$ & $p=0.9591$ \\
\hline \multicolumn{7}{|c|}{ Minimum requirements (base $=$ not known) } \\
\hline known & 2.942 & $1.390-6.226$ & $p=0.0048$ & - & & \\
\hline \multicolumn{7}{|c|}{ Specialty (base $=$ others) } \\
\hline General medicine & 3.442 & $1.827-6.484$ & $p=0.0001$ & 4.635 & $2.306-9.316$ & $p<0.0001$ \\
\hline Internal medicine & 2.689 & $1.201-6.022$ & $p=0.0162$ & 3.189 & $1.269-8.016$ & $p=0.0137$ \\
\hline Psychiatry & 2.338 & $0.851-6.421$ & $p=0.0994$ & 1.956 & $0.693-5.519$ & $p=0.2047$ \\
\hline
\end{tabular}


Table 4 Reasons for medical reporting (only physicians with reports)

\begin{tabular}{|c|c|c|c|c|c|}
\hline & $\begin{array}{l}\text { Safety of the } \\
\text { patients }(\%)\end{array}$ & $\begin{array}{l}\text { Safety of all road } \\
\text { users (\%) }\end{array}$ & $\begin{array}{l}\text { Legal protection } \\
\text { of the physician (\%) }\end{array}$ & Patient's noncompliance (\%) & Other reasons $(\%)$ \\
\hline Total $(n=127)$ & 58 & 98 & 35 & 31 & 2 \\
\hline \multicolumn{6}{|l|}{ Sex } \\
\hline Male $(n=121)$ & 57 & 98 & 33 & 30 & 3 \\
\hline Female $(n=5)$ & 80 & 100 & 60 & 60 & 0 \\
\hline \multicolumn{6}{|l|}{ Age } \\
\hline$<35$ years $(n=0)$ & - & - & - & - & - \\
\hline $36-45$ years $(n=23)$ & 48 & 100 & 39 & 30 & 9 \\
\hline $46-55$ years $(n=47)$ & 53 & 98 & 34 & 32 & 2 \\
\hline $56-65$ years $(n=48)$ & 67 & 100 & 38 & 27 & 0 \\
\hline$>65$ years $(n=9)$ & 67 & 89 & 11 & 44 & 0 \\
\hline \multicolumn{6}{|l|}{ Years of practice } \\
\hline$<10(n=32)$ & 50 & 97 & 38 & 41 & 6 \\
\hline $11-20(n=37)$ & 51 & 100 & 38 & 30 & 3 \\
\hline $21-30(n=48)$ & 65 & 100 & 31 & 23 & 0 \\
\hline$>30(n=10)$ & 70 & 90 & 30 & 40 & 0 \\
\hline \multicolumn{6}{|l|}{ Specialty } \\
\hline General medicine $(n=75)$ & 60 & 99 & 29 & 24 & 4 \\
\hline Internal medicine $(n=21)$ & 43 & 100 & 29 & 29 & 0 \\
\hline Psychiatry $(n=8)$ & 80 & 100 & 70 & 70 & 0 \\
\hline Other $(n=21)$ & 57 & 95 & 43 & 38 & 0 \\
\hline
\end{tabular}

Because of multiple answers the sum can be $>100 \%$

Table 5 Reasons against medical reporting (only physicians with no reports)

\begin{tabular}{|c|c|c|c|c|c|c|c|}
\hline & $\begin{array}{l}\text { No relevance to } \\
\text { specialty }(\%)\end{array}$ & $\begin{array}{l}\text { Patient } \\
\text { protection }(\%)\end{array}$ & $\begin{array}{l}\text { Ignorance of } \\
\text { reporting } \\
\text { rights }(\%)\end{array}$ & $\begin{array}{l}\text { No reason to } \\
\text { report }(\%)\end{array}$ & $\begin{array}{l}\text { Protection of the } \\
\text { physician/patient } \\
\text { relationship (\%) }\end{array}$ & $\begin{array}{l}\text { Protection against } \\
\text { threatened social } \\
\text { isolation }(\%)\end{array}$ & $\begin{array}{l}\text { Other reasons } \\
(\%)\end{array}$ \\
\hline Total $(n=187)$ & 24 & 3 & 11 & 63 & 11 & 9 & 21 \\
\hline \multicolumn{8}{|l|}{ Sex } \\
\hline Male $(n=141)$ & 24 & 4 & 9 & 65 & 13 & 8 & 21 \\
\hline Female $(n=45)$ & 24 & 0 & 18 & 58 & 7 & 11 & 20 \\
\hline \multicolumn{8}{|l|}{ Age } \\
\hline$<35$ years $(n=3)$ & 0 & 0 & 0 & 33 & 0 & 0 & 67 \\
\hline $36-45$ years $(n=45)$ & 25 & 5 & 14 & 57 & 7 & 11 & 9 \\
\hline $46-55$ years $(n=71)$ & 23 & 3 & 14 & 69 & 13 & 6 & 27 \\
\hline $56-65$ years $(n=58)$ & 29 & 0 & 5 & 62 & 12 & 10 & 24 \\
\hline$>65$ years $(n=10)$ & 10 & 10 & 10 & 70 & 20 & 10 & 0 \\
\hline \multicolumn{8}{|l|}{ Years in practice } \\
\hline$<10(n=65)$ & 25 & 2 & 9 & 62 & 5 & 8 & 19 \\
\hline $11-20(n=60)$ & 28 & 5 & 18 & 60 & 18 & 8 & 28 \\
\hline $21-30(n=49)$ & 18 & 0 & 2 & 69 & 10 & 8 & 18 \\
\hline$>30(n=11)$ & 27 & 9 & 18 & 64 & 18 & 18 & 0 \\
\hline \multicolumn{8}{|l|}{ Specialty } \\
\hline $\begin{array}{l}\text { General medicine } \\
(n=61)\end{array}$ & 5 & 5 & 15 & 60 & 23 & 15 & 25 \\
\hline $\begin{array}{l}\text { Internal medicine } \\
(n=25)\end{array}$ & 8 & 0 & 0 & 84 & 8 & 4 & 12 \\
\hline Psychiatry $(n=18)$ & 33 & 0 & 11 & 78 & 6 & 11 & 28 \\
\hline Other $(n=84)$ & 41 & 2 & 11 & 56 & 5 & 5 & 20 \\
\hline
\end{tabular}

Because of multiple answers the sum can be $>100 \%$ 
Table 6 Acceptance of discretionary/mandatory medical reporting

\begin{tabular}{|c|c|c|c|c|c|c|}
\hline & \multicolumn{3}{|c|}{ Abolish discretionary reporting? } & \multicolumn{3}{|c|}{ Introduce mandatory reporting? } \\
\hline & Yes \% $(n)$ & No $\%(n)$ & No opinion \% $(n)$ & Yes \% $(n)$ & No \% $(n)$ & No opinion $\%(n)$ \\
\hline Total & $1(4)$ & $97(307)$ & $2(5)$ & $29(92)$ & $68(213)$ & $3(10)$ \\
\hline \multicolumn{7}{|l|}{ Sex } \\
\hline Male & $2(4)$ & $97(258)$ & $1(3)$ & $27(70)$ & $70(185)$ & $3(9)$ \\
\hline Female & $0(0)$ & $96(47)$ & $4(2)$ & $41(20)$ & $57(28)$ & $2(1)$ \\
\hline \multicolumn{7}{|l|}{ Age } \\
\hline$<35$ years & $0(0)$ & $100(3)$ & $0(0)$ & $50(1)$ & $50(1)$ & $0(0)$ \\
\hline $36-45$ years & $0(0)$ & $99(66)$ & $1(1)$ & $32(22)$ & $62(42)$ & $6(4)$ \\
\hline $46-55$ years & $2(2)$ & $97(116)$ & $1(1)$ & $29(35)$ & $70(83)$ & $1(1)$ \\
\hline $56-65$ years & $1(1)$ & $96(103)$ & $3(3)$ & $26(28)$ & $69(73)$ & $5(5)$ \\
\hline$>65$ years & $5(1)$ & $95(18)$ & $0(0)$ & $26(5)$ & $74(14)$ & $0(0)$ \\
\hline \multicolumn{7}{|l|}{ Years in practice } \\
\hline$<10$ & $1(1)$ & $98(95)$ & $1(1)$ & $35(34)$ & $62(60)$ & $3(3)$ \\
\hline $11-20$ & $1(1)$ & $96(94)$ & $3(3)$ & $28(27)$ & $70(69)$ & $2(2)$ \\
\hline $21-30$ & $2(2)$ & $97(95)$ & $1(1)$ & $26(25)$ & $69(67)$ & $5(5)$ \\
\hline$>30$ & $0(0)$ & $100(21)$ & $0(0)$ & $24(5)$ & $76(16)$ & $0(0)$ \\
\hline \multicolumn{7}{|l|}{ Specialty } \\
\hline General medicine & $1(2)$ & 98 (132) & $1(1)$ & $27(36)$ & $70(95)$ & $3(4)$ \\
\hline Internal medicine & $0(0)$ & $100(47)$ & $0(0)$ & $26(12)$ & $74(35)$ & $0(0)$ \\
\hline Psychiatry & $0(0)$ & $96(27)$ & $4(1)$ & $29(8)$ & $71(20)$ & $0(0)$ \\
\hline Other & $2(2)$ & $95(101)$ & $3(3)$ & $34(36)$ & $60(63)$ & $6(6)$ \\
\hline
\end{tabular}

estimate can be cautiously deduced from the investigation results.

Forty percent of the physicians (male $46 \%$, female $10 \%$ ) have already notified the department of motor vehicles about patients. This number as well as the mean medical frequency of reporting of 0.31 patients in the past year and of 1.00 patients the past 5 years seems to be quite low. Thus, in the ambulant sector of the examined region, there are between 620 and 950 inhabitants for one physician [23]. Moreover, it is interesting to keep in mind the prevalence of health disorders that are medically relevant to road use: in 2007, for example, $2.2 \%$ of the Swiss population were being treated for diabetes mellitus and $2.7 \%$ due to depression; $2.6 \%$ of the Swiss population take sleeping medication daily, while $0.6 \%$ consume drugs such as heroin, cocaine, amphetamines, and ecstasy, among others; $14.2 \%$ drink alcohol more than once a day [24]. Also, in 2009 , as a consequence of limited medical reporting, only 3,139 (of 97,692) driver's license revocations were imposed in Switzerland as a result of somatic illnesses [25]. In international comparison, the portion of the physicians that have notified the licensing authorities is nevertheless large: in the investigation of Drickamer et al., it amounted to only $14 \%$ [21].

To be kept in mind is that the portion of the reporting physicians and the average medical reporting rate has to do - as was already mentioned-with all specialties, also with those that have little contact with the driving fitness problems. For general practitioners who take over the coordination of patient care by specialists (case management) very often in Switzerland, the mean reporting numbers are clearly larger, but in the overall view still appear small (0.48 reports in the past year, 1.45 reports in the past 5 years). The applied logistic regression showed that the specialty "general medicine" is a parameter with significant influence on reporting potentially unfit drivers.

In the responses, male physicians were overrepresented. These reported more often patients to the licensing authorities than female physicians $(p<0.0001)$. The logistic regression analysis demonstrated male sex as one of the significant influencing factors for reporting. As reasons for this fact, a more impersonal access to driving fitness problems by male physicians and a higher portion of parttime work in the group of female physicians can be discussed. The difference between male and female physicians should be taken into consideration in the continuing medical education.

Seventy-nine percent of the responding physicians indicated knowing the current medical requirements for driving in Switzerland. A contribution of knowledge on reporting behavior seems plausible, but in the logistic 
analysis, the knowledge of minimal requirements was not a factor with significant influence on reporting ( $p$ value just above the level of statistical significance). This surprising fact should be object of further investigations.

Physicians who have already reported patients gave as the main reason the safety of the other drivers as well as that of the patient himself or herself $(98 \%$ and $58 \%$, respectively, for all physicians). The preponderance of public safety as compared with the individual interest of a driver as the reason for a report is also shown by Marshall et al. [16] in their investigation in which $92.5 \%$ of the queried physicians endorse reporting of those potentially unfit to drive. Similar results were obtained in an investigation by Cable et al. according to which $86 \%$ of the physicians would report a demented patient, even against his or her will, and $72.9 \%$ also against the will of the patient's family to the licensing authorities [26].

Psychiatrists provide more frequently than physicians of other specialties as reason for notifying the licensing authorities the legal protection of physicians and noncompliance of the patients ( $70 \%$ as opposed to $29-43 \%$ and $24-38 \%$, respectively). This can be best explained with the fact that psychiatrists care - more frequently than other specialtiesfor patients with a high proportion of driving fitness problems and disease-related restricted compliance.

With regard to the characteristics of psychiatric disorders what cannot be explained is that $1 / 3$ of the psychiatrists, who have up till now made no reports, claim a missing relevance of the driving fitness problems to their specialty (general practitioners and internists $5 \%$ and $8 \%$, respectively).

As the most frequent reason (with 63\%) that a physician up until now has never reported a patient to the licensing authorities, a missing indication was given. To us, this number appears very high but can nevertheless be partially explained by the fact that in the present investigation, physicians from specialties were also addressed in whose field of activity driving fitness problems have only little or as good as no importance (e.g., pediatrics).

The agreement of physicians concerning discretionary medical reporting in cases of poor or missing driving fitness was very clear. The legal article, introduced in 1975, appears to be broadly accepted by physicians - independent of sex, age, and specialty. The satisfaction with the current legal situation is also shown in that only a scant $30 \%$ were for introducing mandatory reporting. Whether this would lead to an increase of traffic safety as a result of early detection of potentially unfit drivers is contested. Thus, in 2000, a Canadian investigation showed that a mandatory reporting of patients with cardiac disease had a negligible influence on morbidity and mortality in automobile accidents [27]. Sindwani et al. are of the opinion that mandatory reporting is not a satisfactory means of bringing patients with vestibular complaints and who are unfit to drive to the attention of the licensing authorities [15]. In addition, the risk of accidents of epileptics would not be reduced by mandatory reporting [28]. A negative influence of mandatory reporting on the physician/patient relationship is repeatedly discussed in the literature $[12,16,29]$. In contrast, Meuser et al. showed that the right of reporting potentially unfit drivers led to a reduction of the collision frequency of older drivers [30]. Currently, for Switzerland, there is no study that has investigated the influence of discretionary medical reporting on traffic safety in terms of hard endpoints such as accident frequency.

\section{Conclusions}

The great majority of the queried physicians protects discretionary reporting of potentially unfit drivers as is currently in force in Switzerland. The low number of reports per physician shows clearly the importance and necessity of regular continuing education concerning traffic medicine. Investigations made to ascertain the effectiveness of discretionary reporting on hard endpoints such as, for example, accident frequency, should be carried out.

Conflict of interest The authors declare that they have no conflict of interest.

\section{References}

1. Galski T, Vocaturo L, Galski TM (2009) Driving, medical illness, and medications. In: Schultheis MT, DeLuca J, Chute DL (eds) Handbook for the assessment of driving capacity, 1st edn. Elsevier, San Diego, pp 160-168

2. Penning R, Veldstra JL, Daamen AP, Olivier B, Verster JC (2010) Drugs of abuse, driving and traffic safety. Curr Drug Abuse Rev 3 (1):23-32

3. Aschkenasy MT, Drescher MJ, Ratzan RM (2006) Physician reporting of medically impaired drivers. J Emerg Med 30(1):29-39

4. Galski T, McDonald MA (2009) Driving and law. In: Schultheis MT, DeLuca J, Chute DL (eds) Handbook for the assessment of driving capacity, 1st edn. Elsevier, San Diego, pp 193-195, 217-229

5. Beran RG (2005) Analysis and overview of the guidelines for assessing fitness to drive for commercial and private vehicle drivers. Intern Med J 35:364-368

6. Peitz J, Hoffmann-Born H (2008) Arzthaftung bei problematischer Fahreignung. Kirschbaum, Bonn, p 17

7. Simpson CS, Hoffmaster B, Mitchell LB, Klein GJ (2004) Mandatory physician reporting of drivers with cardiac disease: ethical and practical considerations. Can J Cardiol 20(13):13291334

8. The Federal Authorities of the Swiss Confederation. Federal Act of 19 Decemeber 1958 on Street Traffic (Strassenverkehrsgesetz). http://www.admin.ch/ch/d/sr/741 01/index.html. Accessed 06 September 2010

9. Swiss Federal Statistical Office. Permanent resident population per canton. http://www.bfs.admin.ch/bfs/portal/en/index/themen/ 
01/02/blank/key/raeumliche_verteilung/kantone__gemeinden. html. Accessed 06 September 2010

10. Economic Development and Tourism Agency of Grisons. Population data. http://www.gr.ch/DE/INSTITUTIONEN/VERWALTUNG/ DVS/AWT/DIENSTLEISTUNGEN/VOLKSWIRTSCHAFTLI CHEGRUNDLAGEN/Seiten/Bevoelkerung.aspx. Accessed 06 September 2010

11. Swiss Medical Association. Online database of Swiss Physicians. www.doctorfmh.ch. Accessed 10-12 May 2010.

12. Jang RW, Man-Son-Hing M, Molnar FJ, Hogan DB, Marshall SC, Auger J, Graham ID, Korner-Bitensky N, Tomlinson G, Kowgier ME, Naglie G (2007) Family Physicians' attitudes and practices regarding assessments of medical fitness to drive in older persons. J Gen Intern Med 22(4):531-543

13. Chang G, Astrachan B, Weil U, Bryant K (1992) Reporting alcohol-impaired drivers: results from a national survey of emergency physicians. Ann Emerg Med 21(3):284-290

14. McLachlan RS (1997) Medical conditions \& driving: legal requirements \& approach of neurologists. Med Law 16(2):269275

15. Sindwani R, Parnes LS (1997) Reporting of vestibular patients who are unfit to drive: survey of canadian otolaryngologists. J Otolaryngol 26(2):104-111

16. Marshall SC, Gilbert N (1999) Saskatchewan physicians' attitudes and knowledge regarding assessment of medical fitness to drive. CMAJ 160(12):1701-1704

17. King D, Benbow SJ, Barrett JA (1992) The law and medical fitness to drive - a study of doctors' knowledge. Postgrad Med J 68:624-628

18. Ménard I, Korner-Bitensky N, Dobbs B, Casacalenda N, Beck PR, Dippsych CM, Gélinas I, Molnar FJ, Naglie G (2006) Canadian psychiatrists' current attitudes, practices, and knowledge regarding fitness to drive in individuals with mental illness: a crosscanada survey. Can J Psychiatry 51(13):836-846

19. Shanahan EM, Sladek RM, Phillips P (2007) Medical aspects of fitness to drive. What do public hospital doctors know and think? Intern Med J 37:372-376
20. Wilson LR, Kirby NH (2008) Individual differences in south australian general practitioners' knowledge, procedures and opinions of the assessment of older drivers. Australas J Ageing 27(3):121-125

21. Drickamer MA, Marottoli RA (1993) Physician responsibility in driver assessment. Am J Med Sci 306(5):277-281

22. Frampton A (2003) Who can drive home from emergency department? A questionnaire based study of emergency physicians' knowledge of DVLA guidelines. Emerg Med J 2003 (20):526-530

23. Swiss Federal Statistical Office. Inventory of physicians, dentists and pharmacies per canton 1990-2008. http://www.bfs.admin.ch/ bfs/portal/de/index/themen/14/03/03/key/01.Document.21521.xls. Accessed 06 September 2010

24. Swiss Federal Statistical Office. Statistical lexicon. http://www. bfs.admin.ch/bfs/portal/de/index/themen/14/22/lexi.topic.1.html. Accessed 06 September 2010

25. Swiss Federal Roads Office. Statistics of administrative measures 2009. http://www.astra.admin.ch/dokumentation/00119/00218/index. html?lang=de. Accessed 06 September 2010

26. Cable G, Reisner M, Gerges S, Thirumavalavan V (2000) Knowledge, attitudes, and practices of geriatricians regarding patients with dementia who are potentially dangerous automobile drivers: a national survey. J Am Geriatr Soc 48(1):14-17

27. Simpson CS, Klein GJ, Brennan FJ, Krahn AD, Yee R, Skanes AC (2000) Impact of a mandatory physician reporting system for cardiac patients potentially unfit to drive. Can J Cardiol 16 (10):1257-1263

28. McLachlan RS, Starreveld E, Lee MA (2007) Impact of mandatory physician reporting on accident risk in epilepsy. Epilepsia 48(8):1500-1505

29. Salinsky MC, Wegener K, Sinnema F (1992) Epilepsy, driving laws, and patient disclosure to physicians. Epilepsia 33(3):469472

30. Meuser TM, Carr DB, Ulfarsson GF (2009) Motor-vehicle crash history and licensing outcomes for older drivers reported as medically impaired in Missouri. Accid Anal Prev 41(2):246-252 